\title{
DISTRIBUIÇÃO ESPAÇO-TEMPORAL DE CAMARÕES NO PLÂNCTON (DECAPODA: DENDROBRANCHIATA) NA PLATAFORMA CONTINENTAL DO AMAZONAS
}

\author{
Silva, L.S. ${ }^{1,}$; Cavalcante-Braga, D.V. ${ }^{1}$ \& Martinelli-Lemos, J.M. ${ }^{1}$ \\ ${ }^{1}$ Grupo de Pesquisa em Crustáceos da Amazônia (GPECA), Laboratório de Biologia Pesqueira e Manejo dos \\ Recursos Aquáticos, Instituto de Ciências Biológicas, Universidade Federal do Pará (UFPA), Campus Belém. \\ *Autor correspondente: leilianess@gmail.br
}

Os camarões representam importante grupo de crustáceos, tanto em sua fase larval como componente do plâncton e da cadeia trófica aquática, quanto em sua fase bentônica/nectônica. Neste trabalho, investigamos a composição taxonômica e a distribuição espacial e temporal dos camarões Dendrobranchiata presentes no plâncton na Plataforma Continental do Amazonas (PCA), em um transecto entre a foz dos rios Amazonas e Pará. Foram analisadas 42 amostras, resultado de 7 campanhas realizadas sazonalmente de julho/2013 a janeiro/2015, em 6 locais na área da Plataforma Continental do Amazonas abrangendo uma extensão de $\approx 250 \mathrm{Km}$ em direção ao Talude Continental. O plâncton foi coletado com arrastos oblíquos (malha $200 \mu \mathrm{m}$ ), sendo encontrados 9 táxons: Belzebub faxoni, Lucifer typus, Acetes spp., Sergestes sp, Sicyonia spp., Solenocera spp., Penaeus spp., Xiphopenaeus kroyeri e Penaeidae spp. Belzebub faxoni esteve dominante na PCA, apresentando as maiores densidades (média: $2 \mathrm{org} . / \mathrm{m}^{3} \pm 6,28$ desvio padrão), seguido de Acetes spp. $\left(0,18 \mathrm{org} . / \mathrm{m}^{3} \pm 0,59\right)$ e Sicyonia spp. (0,02 larvas $\left./ \mathrm{m}^{3} \pm 0,07\right)$. Com uma Análise de Redundância Canônica (RDA), observamos que os Acetes spp. estiveram negativamente relacionados com a clorofila-a e temperatura, e os Luciferidae correlacionados positivamente com a variável temporal (mês). As mysis III de Solenoceridae e os camarões Penaeidae estiveram correlacionados positivamente com a distância da costa. A vazão do Rio Amazonas exerceu grande influência na dinâmica da PCA, principalmente nos fatores salinidade e da clorofila-a, explicando a distribuição da assembleia dos camarões, principalmente para os Penaeidae, que apresentaram maior densidade no período de menor vazão do Rio Amazonas ( $Z=-3,23 ; p=0,001)$. Destacamos que apesar da baixa densidade larval de Penaeus e Xiphopenaeus, a presença contínua em todos os meses e locais amostrados ao longo de toda a PCA comprova a importância dessa área como berçário para as espécies de camarões com relevante importância econômica. Destacamos também a PCA como uma área prioritária para a biodiversidade e de extrema importância para o desenvolvimento dos camarões Dendrobranchiata.

Palavras-chave: Belzebub faxoni, estágios de desenvolvimento, Penaeidae, Sergestidae, zooplâncton.

Financiamento: INCT-Ambientes Marinhos Tropicais (CNPq nº 565054/2010-4). 